
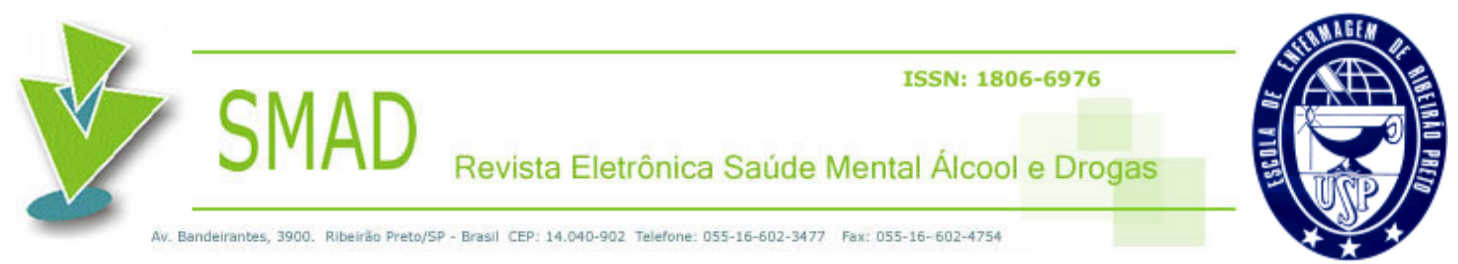

\title{
Processo de CompetênCia Cultural nos Cuidados de EnFERMAGem a Usuários de Drogas Injetáveis no Projeto de ReduÇão de Danos de Porto Alegre - Brasil Cristiano Gregis $^{1}$; Jussara Gue Martini ${ }^{2}$
}

Resumo

O objetivo deste estudo é discutir as intervenções de enfermagem nos espaços de atuação de um Programa de Redução de Danos (PRD), centradas no cuidado de enfermagem transcultural. O trabalho de campo foi desenvolvido no âmbito do Programa de Redução de Danos de Porto Alegre, no período de 1998 a 2000, a partir do cuidado de Enfermagem aos usuários abordados pela equipe do PRD. Concluí-se que, para além da troca de seringas, a prática de cuidados de enfermagem, com competência, cultural permite a compreensão da complexidade implicada com a abordagem das questões relacionadas ao uso de drogas na sociedade.

Palavras-chave: enfermagem, cuidado transcultural, usuários de drogas injetáveis, programa de redução de danos

\section{Cultural Competence Process in Nursing Care to InJectable Drugs Users in the Damage Reduction Project in Porto Alegre, Brazil}

Abstract

This study aims to discuss nursing interventions in the activities of a Damage Reduction Program (PRD), centered in transcultural nursing care. The field work was developed in the PRD in Porto Alegre, from 1998 to 2000, starting from nursing care to addicts attended by PRD staff. We concluded that, beyond the syringes exchange, nursing care practice with cultural competence allows for a comprehension of the complexity implied in the approach of questions related to drugs use in society.

Keywords: nursing, transcultural care, injectable drug addicts, damage reduction program

\section{Proceso de Competencia Cultural en los Cuidados de EnFERMería a Usuarios de Drogas Inyectables en el Proyecto de Reducción de Daños de Porto Alegre - BRASIL}

Resumen

El objetivo de este estudio es discutir las intervenciones de enfermería en los espacios de actuación de un programa de reducción de daños (PRD), centrado en el cuidado de enfermería transcultural. El trabajo de campo fue desarrollado en el ámbito del Programa de Reducción de Daños de Porto Alegre, en el período de 1998 al 2000, a partir del cuidado de enfermería a los usuarios abordados por el equipo del PRD. Concluímos que, más allá del cambio de jeringas, la práctica de cuidados de enfermería con competencia cultural permite la comprensión de la complejidad implicada con la aproximación de las cuestiones relacionadas al uso de drogas en la sociedad.

Palabras clave: enfermería, cuidado transcultural, usuarios de drogas inyectables, programa de reducción de daños

\footnotetext{
${ }^{1}$ Enfermeiro pela UNISINOS; Especialista em Saúde da Família pela UNIFAP; Mestre em Antropologia pela UFRGS.

${ }^{2}$ Enfermeira, Doutora em Educação; Docente e pesquisadora do Departamento de Enfermagem da Universidade Federal de Santa Catarina e-mail: . jussarague@terra.com.br
}

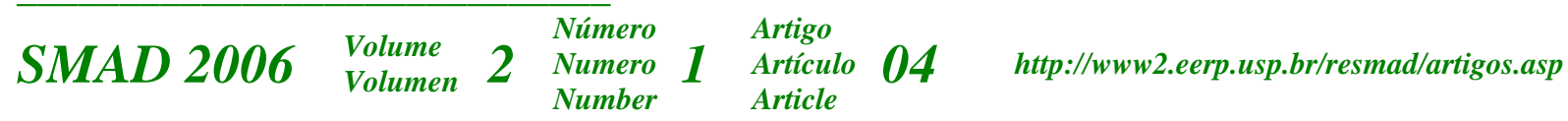




\section{INTRODUÇÃO}

Os problemas de saúde, relacionados ao uso abusivo e indevido de álcool e outras drogas, são relevantes no âmbito da saúde pública. Segundo dados do Ministério da Saúde, estima-se que $10 \%$ da população dos centros urbanos consomem abusivamente substâncias psicoativas ${ }^{(1)}$. Apesar disso, as políticas públicas têm se resumido a reprimir o uso mediante leis que tornam o usuário um criminoso, e o combate ao tráfico de algumas drogas tem se mostrado ineficaz, pois ampliam os danos sociais aos usuários de drogas ilícitas e, no âmbito econômico, sobrevalorizam as substâncias psicoativas ilícitas e diminuem a qualidade dessas para o consumidor final ${ }^{(2-3)}$. Frutos dessas políticas, no setor saúde procurou-se evitar o uso de drogas com campanhas de prevenção que valorizavam o “mal das drogas”, que também tem efeito negativo, pois se sabe que a toxicomania não é uma questão de falta de informação ${ }^{(4)}$.

O atraso no enfrentamento eficaz da epidemia de HIV entre pessoas que fazem uso indevido de drogas injetáveis resultou na alta incidência de portadores do vírus HIV e doentes de aids nessas populações, dentre outros agravos à saúde. Cerca 25\% dos casos de AIDS estão direta ou indiretamente relacionados à categoria de exposição ao uso de drogas injetáveis (Usuários de Drogas Injetáveis - UDI) ${ }^{(1)}$. Também são citados dados da Pesquisa Ajude Brasil II - 2001, estudo realizado entre UDI, acessados por projetos de redução de danos, que “apontam que 38,6\% concederam agulhas e seringas a outra pessoa, enquanto 35,9\% utilizaram agulhas/seringas de outra pessoa . A taxa de soroprevalência de HIV é de $36,5 \%$

No sentido de interromper a cadeia de transmissão do HIV entre UDI, desde 1989 é implementada, em algumas capitais, a estratégia de troca de seringas com pessoas que usam drogas injetáveis, dentre outras ações de Redução de Danos ao uso de drogas injetáveis. No

\begin{tabular}{|c|c|c|c|c|}
\hline SMAD 2006 & $\begin{array}{l}\text { Volume } \\
\text { Volumen }\end{array}$ & $\begin{array}{l}\text { Número } \\
\text { Numero } 1 \\
\text { Number }\end{array}$ & $\begin{array}{l}\text { Artigo } \\
\text { Artículo } 04 \\
\text { Article }\end{array}$ & v2.eerp.usp.br/resmad/artigos.asp \\
\hline
\end{tabular}


Projeto de Redução de Danos (PRD) da Política Municipal de Controle de DST/AIDS da Secretaria Municipal de Saúde de Porto Alegre-RS, os autores participaram do enfrentamento dos problemas de saúde relacionados ao consumo abusivo e indevido de álcool e outras drogas, em particular a epidemia de aids entre essas pessoas, do segundo semestre de 1998 ao primeiro semestre de 2000.

A partir da análise das ações de enfermagem desenvolvidas nesse PRD, esse artigo propõe a abordagem dos problemas de saúde de pessoas que fazem uso indevido de drogas injetáveis centrada no cuidado de enfermagem. Ao assinalar as habilidades transculturais necessárias para que o cuidado seja eficaz a essas pessoas, soma-se esforços à proposta da política de atenção integral a usuários de álcool e outras drogas no sentido de criar dispositivos extra-hospitalares, fazendo uso "da lógica ampliada de redução de danos, realizando uma procura ativa e sistemática das necessidades a serem atendidas, de forma integrada ao meio cultural e à comunidade em que estão inseridos” ${ }^{(1)}$.

\section{O PROCESSO DE COMPETÊNCIA CULTURAL NOS CUIDADOS DE ENFERMAGEM}

O papel da diferença cultural no planejamento e implementação de cuidados de enfermagem iniciou-se após a Segunda Guerra, quando os profissionais de enfermagem norteamericanos voltavam do estrangeiro e trocavam experiências sobre as práticas de cuidados em outras culturas ${ }^{(5)}$. A partir daí, cresce a aliança entre a ciência antropológica e a enfermagem por ambas se identificarem com as pessoas, famílias e comunidades, com os temas estudados, a observação como forma de produzir conhecimento, e pela visão integral do homem (idem). Na década de 1960, irá se desenvolver a proposta da teoria de diversidade e universidade cultural do cuidado, desenvolvida por Madeleine Leininger, que será posteriormente incluída

\begin{tabular}{|c|c|c|c|c|}
\hline SMAD 2006 & $\begin{array}{l}\text { Volume } \\
\text { Volumen }\end{array}$ & $\begin{array}{l}\text { Número } \\
\text { Numero } 1 \\
\text { Number }\end{array}$ & $\begin{array}{l}\text { Artigo } \\
\text { Artículo } 04 \\
\text { Article }\end{array}$ & http://www2.eerp.usp.br/resmad/artigos.asp \\
\hline
\end{tabular}


como uma das grandes teorias que embasam a enfermagem científica brasileira. Nessa teoria, o conhecimento de significados e práticas, derivados de visões de mundo, de fatores de estrutura social, dos valores culturais, do contexto ambiental e dos usos de linguagem é essencial para guiar a enfermagem no fornecimento de cuidado culturalmente competente ${ }^{(6)}$. A autora apresenta o campo da enfermagem transcultural, definido como "um subcampo ou ramo culto da enfermagem, que focaliza o estudo comparativo e a análise de culturas, no que diz respeito à enfermagem e às práticas de cuidado à saúde-doença, crenças e valores, buscando a oferta de serviços de cuidado em enfermagem significativos e eficazes às pessoas, de acordo com seus valores e contexto de saúde-doença” (6).

Ao postular a universalidade do cuidado, a autora rompe com o biologicismo das ciências da saúde onde a enfermagem está inserida, pois seu objeto de trabalho não estaria restrito ao campo biomédico. Defende-se como objeto de trabalho da enfermagem o cuidado profissional, definido como "aqueles modos humanísticos e científicos, cognitivamente apreendidos, de ajudar ou permitir que um indivíduo, família ou comunidade receba serviços personalizados através de processos, técnicas e padrões de cuidado culturalmente específicos ou relacionados a essa cultura no sentido de melhorar ou manter uma condição de saúde favorável para vida ou morte” (7).

A produção científica sobre as dimensões socioculturais da saúde/doença no Brasil expandiu e amadureceu na última década ${ }^{(8)}$. Além da diferença étnico-racial, outras demarcações sociais podem produzir formas próprias de pensar o corpo e o processo saúdedoença. Aí temos a diferença sexual, as diferentes classes econômicas, as filiações religiosas, dentre outras e, neste caso específico a daquelas pessoas que realizam práticas demarcadas socialmente como indevidas ou “marginais". 
Pensar como as diferenças culturais se reproduzem e se hibridizam, desafiando o contexto urbano, racionalizado das cidades, é um desafio para a antropologia. É nesse sentido que se entende que utilizar uma classificação para as práticas de cuidados a partir de conceitos rígidos como aqueles desenvolvidos na teoria de enfermagem transcultural de Leininger pode levar à atitude intelectual de retificar a cultura, ou em demarcar "barreiras culturais". Identificam-se as dificuldades e ambigüidades no uso do conceito de acomodação/negociação cultural do cuidado da teoria da enfermagem transcultural de Leininger e aponta a necessidade da crítica dessa teoria ${ }^{(9)}$. Ao estudar o cuidado leigo e profissional em uma vila da Tanzânia, a partir da teoria cultural do cuidado de Leininger, avalia como rígida sua concepção de cultura para compreender o cuidado numa sociedade em transformação e identificar os aspectos dinâmicos da cultura ${ }^{(10)}$.

Descreve-se um modelo que inicia com o desejo, com a aspiração profissional em prestar o cuidado efetivo para todos os clientes, conforme a autora "as pessoas não se cuidam tanto quanto você sabe até eles saberem quanto você se importa” por essas pessoas como seres humanos únicos ${ }^{(11)}$.

Ao pensar que cultura é o que o outro possui, os profissionais de saúde objetivam a cultura e isso provoca a distância dos usuários dos serviços de saúde ${ }^{(12)}$. Assim marginalizase a cultura e a etnia dos pacientes e minimiza-se a responsabilidade do profissional enfermeiro de acessar a cultura na prática, ou seja, é um problema da cultura do usuário do serviço. Os autores propõem inverter o problema e ver essas barreiras para o cuidado na cultura biomédica, treinamento insuficiente do profissional e no sistema de saúde.

A próxima etapa no processo de competência cultural é a busca de conhecimento cultural do indivíduo ou grupo, sua visão sobre o corpo, sobre o processo saúde-doença, sobre

\begin{tabular}{|c|c|c|c|c|}
\hline SMAD 2006 & $\begin{array}{l}\text { Volume } \\
\text { Volumen }\end{array}$ & $\begin{array}{l}\text { Número } \\
\text { Numero } 1 \\
\text { Number }\end{array}$ & $\begin{array}{l}\text { Artigo } \\
\text { Artículo } 04 \\
\text { Article }\end{array}$ & http://www2.eerp.usp.br/resmad/artigos.asp \\
\hline
\end{tabular}


as formas daquele grupo cuidar-se e curar-se, quais pessoas possuem esse conhecimento e são os agentes legítimos de cura.

A partir daí, o profissional poderá desenvolver a sensibilidade ou habilidade cultural necessária para realizar a avaliação dos problemas de saúde daquela pessoa ou coletividade, seja na entrevista e exame físico, seja no diagnóstico da situação de saúde da comunidade e desenvolver os cuidados ${ }^{13}$. Nos encontros culturais podem ser necessárias habilidades comunicacionais, como conhecer outro idioma ou trabalhar com um interprete. O modelo pode ser esquematizado como apresentado a seguir.

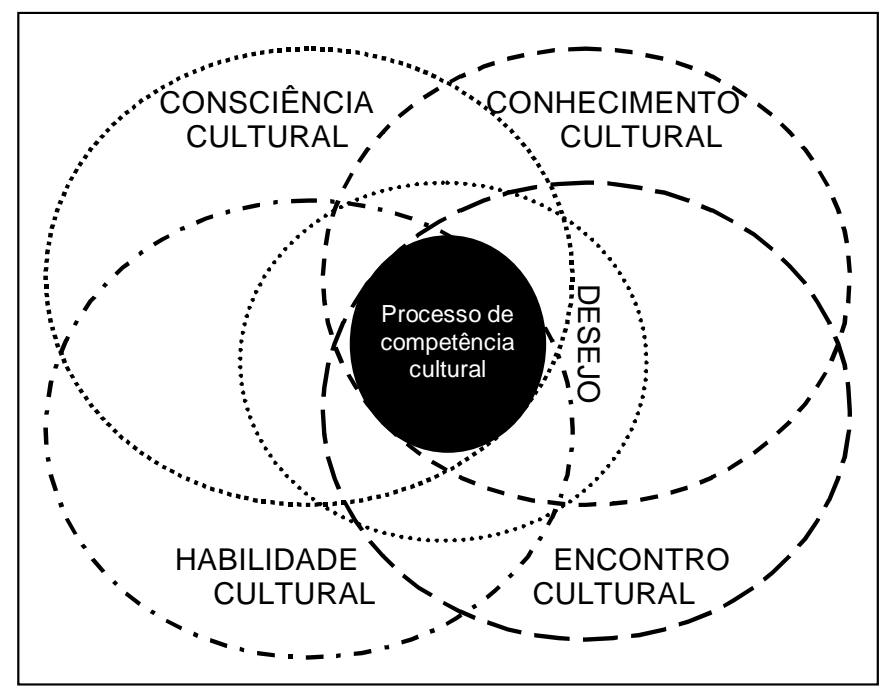

Figura I - Processo de competência cultural na assistência de serviços de saúde ${ }^{(14) .}$.

O processo de competência cultural na enfermagem é diferente da atitude caritativa que marcou a história da enfermagem ${ }^{(15)}$. É outra forma de racionalização da atenção à saúde no planejamento, assistência e avaliação dos cuidados de enfermagem a partir da contribuição das ciências humanas, em particular a antropologia. Ou seja, pensar um processo de competência cultural na prática de cuidados à saúde é buscar sua eficiência nas diferentes coletividades em que ele possa ser aplicado.

SMAD $2006 \quad \begin{aligned} & \text { Volume } \\ & \text { Volumen }\end{aligned} 2 \begin{aligned} & \text { Número } \\ & \text { Numero } 1\end{aligned} \begin{aligned} & \text { Artigo } \\ & \text { Number } \\ & \text { Article }\end{aligned} 04 \quad$ http://www2.eerp.usp.br/resmad/artigos.asp




\section{CUIDADOS A USUÁRIOS DE DROGA INJETÁVEL NO PROCESSO DE COMPETÊNCIA CULTURAL}

O contexto maior onde se inserem as práticas de cuidado em questão é o das ações de saúde, frutos da política de controle da infecção pelo vírus HIV e outros danos à saúde entre usuários de droga injetável no Brasil, conhecidas como Redução de Danos (RD). As estratégias de RD foram adotadas pela primeira vez por associações de usuários de drogas na Holanda, na década de 1980, com o objetivo de impedir a transmissão de outra doença hemotransmissível, a hepatite C, entre seus pares ${ }^{(16)}$. Dentre outras características dessas estratégias que vêm sendo adotadas pelo Ministério da Saúde, destaca-se o entendimento da dimensão sóciocultural do fenômeno das drogas ${ }^{(1)}$.

Dentre as experiências nacionais, há o Projeto de Redução de Danos (PRD) de Porto Alegre. O projeto foi elaborado em novembro de 1995, com o objetivo de prevenir a transmissão da aids entre Usuários de Drogas Injetáveis ${ }^{(17)}$. em um posto de saúde da rede municipal, onde principiam a ser contatados UDI e iniciou-se o programa de troca de seringas.

Progressivamente, novos UDI foram acessados em diferentes regiões da cidade, onde é feita a troca de seringas. Em meados do ano de 1999, cerca de 90\% das seringas que eram disponibilizadas para usuários de droga injetável retornavam para serem incineradas como lixo contaminado. O trabalho de campo desenvolvia-se em diferentes horários, preferencialmente à noite, turno em que os UDI geralmente estavam indo adquirir a droga ou já a possuíam. A presença de equipamento novo, passível de ser trocado por usados, se tornava interessante. Nisso, tornou-se comum a presença de monitores do projeto em momentos de uso, momentos em que as práticas de uso de droga injetável podiam ser melhor compreendidas.

\begin{tabular}{|c|c|c|c|c|}
\hline SMAD 2006 & $\begin{array}{l}\text { Volume } \\
\text { Volumen }\end{array}$ & $\begin{array}{l}\text { Número } \\
\text { Numero } 1\end{array}$ & $\begin{array}{l}\text { Artigo } \\
\text { Artículo } 04\end{array}$ & http://www2.eerp.usp.br/resmad/artigos.asp \\
\hline
\end{tabular}


A concretização dessas ações de redução de danos não se deu sem dificuldades. Os autores, com a socialização como estudantes de universidade particular, com rotina de estudotrabalho desde a adolescência, descendentes de italianos que participavam de grupos filantrópicos católicos mantendo um relacionamento monogâmico heterossexual estável, contrastavam com as pessoas acessadas. Na pesquisa entre os UDI acessados por projetos de redução de danos, observou-se alta prevalência desemprego, de 82\%, e que um terço dos 284 UDI entrevistados ficaram sem moradia no último ano ${ }^{(18)}$. Cerca de $70 \%$ dos UDI participantes da pesquisa apresentaram história de contravenções e relatos de uma ou mais detenções. O "bom mocismo" poderia distanciar os autores moral e intelectualmente do objetivo de prestar cuidados eficientes a essa população.

A formação como enfermeiro dentro de um paradigma biomédico também trazia dificuldades ao buscar introduzir práticas de cuidado. Num primeiro momento, buscava-se sem sucesso “catequizar” aquelas pessoas com a cultura biomédica. Com o tempo compreende-se que, além dos riscos à saúde comuns a qualquer cidadão de sua sociedade, a população usuária de drogas injetáveis vem sendo alvo da política repressiva ao uso de drogas e sofrendo os danos decorrentes da epidemia de aids e outras doenças hemo-transmissíveis.

Entende-se hoje que a consciência do aumento de casos de AIDS em uma comunidade não é causa suficiente de aumento de comportamentos mais seguros em relação à infecção pelo vírus HIV. Partindo de observação semelhante sobre profissionais do sexo, critica-se o entendimento de que o conhecimento técnico-científico possa ser suficiente para levar as pessoas a mudar de comportamento ${ }^{(19)}$. Discute-se como diferentes grupos interpretam diferentemente os riscos (perigos conhecidos) a partir de seu contexto cultural em que as escolhas fazem sentido ou não ${ }^{(19)}$. Análise semelhante, encontra-se nas entrevistas realizadas com UDI acessados por cinco PRD brasileiros, dentro do projeto Ajude Brasil, onde a autora

\begin{tabular}{|c|c|c|c|c|}
\hline SMAD 2006 & $\begin{array}{l}\text { Volume } \\
\text { Volumen }\end{array}$ & $\begin{array}{l}\text { Número } \\
\text { Numero } 1 \\
\text { Number }\end{array}$ & $\begin{array}{l}\text { Artigo } \\
\text { Artículo } 04 \\
\text { Article }\end{array}$ & http://www2.eerp.usp.br/resmad/artigos.asp \\
\hline
\end{tabular}


conclui que "a percepção de risco dos UDI constitui um complexo de interpretações que articula, sinergicamente, tanto suas vivências cotidianas quanto os discursos dirigidos a este grupo (as " falas" dos programas de saúde)” (20). Essa autora assinala como são bem aceitas as ações de redução de danos, onde existem polêmicas em relação à questão do compartilhamento de seringas que, apesar de reconhecido como forma de transmissão de doenças, pode ser uma forma de solidariedade com o grupo ${ }^{(20)}$.

Passou-se aqui a buscar conhecer a cultura dos usuários de droga injetável encontrados nas ruas e comunidades de Porto Alegre. Diferentes estudos demonstram como o uso de drogas varia nas diferentes sociedades, onde sua cultura determinará os comportamentos devidos e indevidos, ou seja, quando o uso será um problema e quando não será. Ao ressaltar a dimensão sóciocultural dos problemas de saúde relacionados ao uso indevido de drogas, não se descarta a dimensão psicobiológica. Entende-se que essas dimensões atuam sistemicamente na produção do problema das drogas ${ }^{(21)}$, em que a mudança de uma dessas dimensões afeta o todo. A epidemia de aids entre usuários de drogas seria um elemento presente nesse sistema. Por isso, para compreender os problemas de saúde do uso indevido de drogas injetáveis é necessário compreender o contexto sóciocultural, pois qualquer explicação genérica, baseada sob premissas fisiológicas e psicológicas, tende a ficar no nível da rotulação e da estigmatização ${ }^{(22)}$.

A acusação de uso indevido da substância per si nas comunidades estaria mais relacionada ao uso de droga injetável. Em estudo sobre a trajetória social de usuários de droga injetável de uma vila, acessada pelo PRD, demonstra-se como o consumo de drogas pode levar à situação de acusação e marginalização do usuário, que vai se somar à acusação de vítimas-culpadas pelo aumento da epidemia de $\operatorname{AIDS}^{(23)}$. 
Devido à proscrição legal e moral do uso de drogas injetáveis, na comunidade, a pessoa do usuário era estigmatizada como “chinelo” (sic), ou seja, como alguém baixo e sujo. Observou-se que “quando as regras morais são obscuras e contraditórias, há uma tendência para que as crenças de poluição simplifiquem ou esclareçam o ponto em questão" (24). Conforme um UDI parceiro do projeto, "Eu ensino os caras que vêm aqui a usar duas camisinhas, uma por cima da outra (sic)”. Nessa fala, o usuário de drogas explica com satisfação como orientava sua rede de UDI sobre o uso do preservativo masculino. Ao explicar que apenas um preservativo era o recomendado, respondeu que aquelas pessoas precisavam usar dois por serem pessoas diferentes. Essa poluição moral também se objetiva no ambiente. Segundo dados do projeto Ajude Brasil, “o descarte do material usado nas sessões de uso, parece ainda precário. Predominam locais como lixo, bueiro, esgoto, vaso sanitário, além de um percentual relativamente elevado em locais abertos e abandonados”(18). Os locais de uso de droga injetável em que se acessavam os usuários na maioria das vezes eram bastante sujos, onde se acumulavam seringas e equipamentos usados, lixo e excrementos.

De 1986 a 1994, foram acompanhados o total de 521 UDI HIV soropositivos e 237 UDI HIV soronegativos em Amsterdã, pesquisando a incidência de índices e fatores de risco para abscessos de pele no lugar da injeção e episódios de endocardites ${ }^{(25)}$. Um total de 545 abscessos de pele foi reportado por 269 UDI e 17 episódios de endocardites foram observados. Outro achado importante desse estudo é o de que obter seringas de um programa de troca de seringas também é, isoladamente, fator para esses agravos à saúde. Eles concluem que a infecção pelo HIV é um fator de risco independente para esses abscessos e endocardites e que se tornam necessárias outras atividades preventivas, como a limpeza da pele. A partir desse estudo e, das observações aqui realizadas, pode-se concluir que além da troca de

\begin{tabular}{|c|c|c|c|c|}
\hline SMAD 2006 & $\begin{array}{l}\text { Volume } \\
\text { Volumen } 2\end{array}$ & $\begin{array}{l}\text { Número } \\
\text { Numero } 1 \\
\text { Number }\end{array}$ & $\begin{array}{l}\text { Artigo } \\
\text { Artículo } 04 \\
\text { Article }\end{array}$ & http://www2.eerp.usp.br/resmad/artigos.asp \\
\hline
\end{tabular}


seringas, uma intervenção que procure introduzir práticas de autocuidado, como a anti-sepsia do local de injeção, torna-se necessária.

A noção alternativa à de doença, que auxilia a entender essa inscrição na pessoa do usuário desse conflito moral e dos problemas de saúde em seu corpo, é a noção de perturbação físico-moral que se refere "às condições, situações ou eventos de vida considerados irregulares ou anormais pelos sujeitos sociais e que envolvam ou afetem não apenas sua mais imediata corporalidade, mas também sua vida moral, seus sentimentos e sua autorepresentação" (26). Essa forma de interpretar a experiência da doença seria chave para compreender como é interpretada a experiência da doença nas classes populares que, por sua visão holista de mundo, não concebem um problema exclusivamente físico ou exclusivamente moral, ou seja, a separação corpo/mente ${ }^{(26)}$. No caso desta, não basta alguém ser portador do HIV, ou ter lesões decorrentes do uso indevido de droga injetável, para experienciar a condição biomédica de doente, pois essa experiência só existe na incorporação da dimensão moral na acusação de “aidético” e “drogado”. Faz-se necessária a degradação física das manifestações da aids ou do uso indevido de cocaína injetável e a acusação a partir do reconhecimento das outras pessoas.

Pode-se assim, esquematizar o uso indevido de droga injetável como perturbação físico-moral:

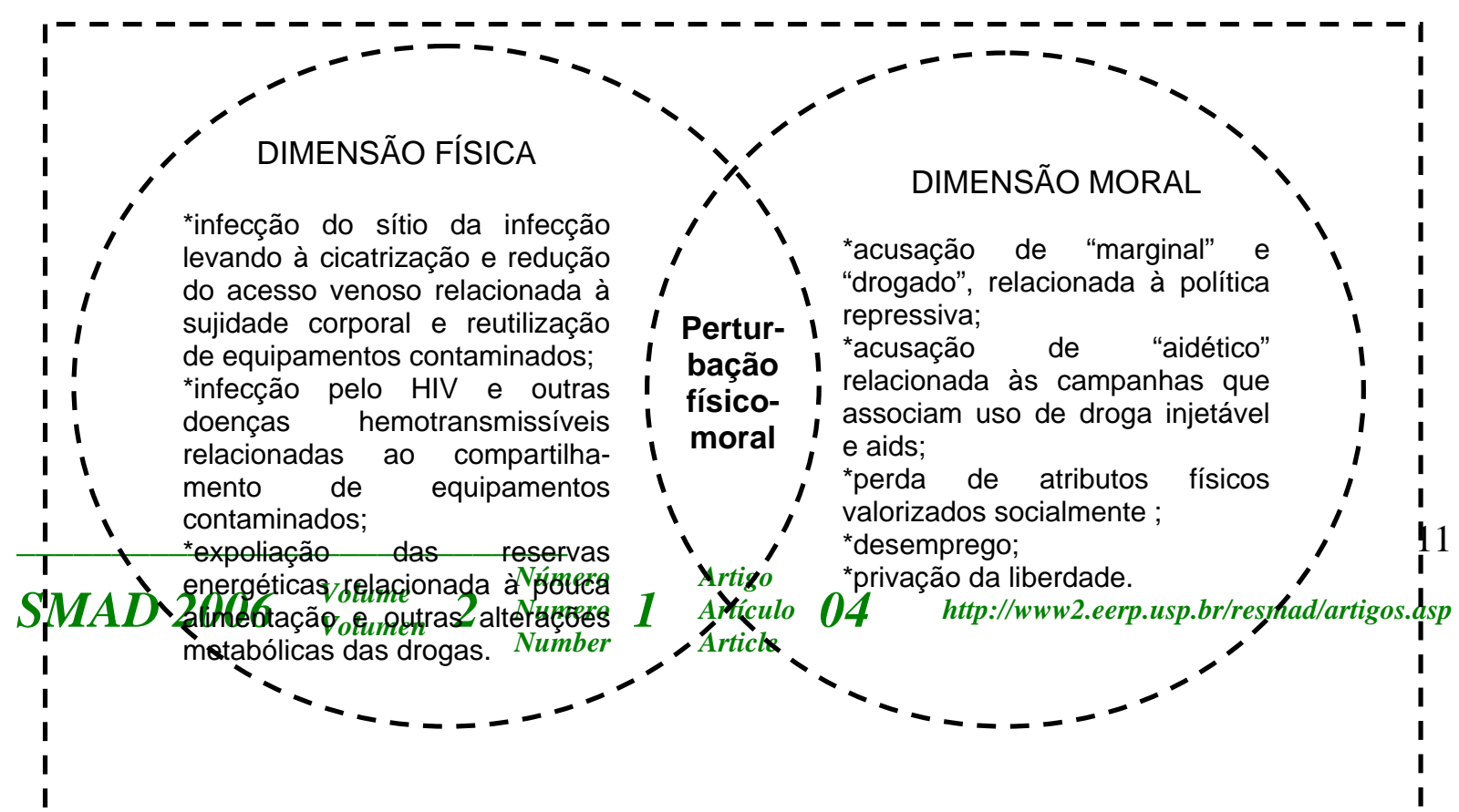


Figura II - Uso indevido de droga injetável como perturbação físico moral

LOCAIS DE USO DE DROGA INJETÁVEL

acúmulo de sujeira e lixo isolamento;

O lócus privilegiado para análise da habilidade cultural é o trabalho de campo (outreach work) nas vilas da periferia e ruas do centro de Porto Alegre, onde se concentravam as ações junto às pessoas que faziam uso indevido de drogas injetáveis. Fora do contexto da clínica das unidades de saúde, nos locais de uso de droga injetável as práticas de saúde se recontextualizam. Diferente do home-care ou internações domiciliares, que seria uma adaptação do ambiente hospitalar à residência do “paciente”, essa recontextualização é de caráter estrutural, pois vai de encontro ao contexto social, política e técnica dessas práticas, ou seja, as próprias relações de poder que a constituem. No trabalho de campo o biopoder normatizador que constitui o contexto da clínica biomédica ${ }^{(27)}$, que predomina no setor saúde, é reduzido, pois o usuário determina os cuidados com sua saúde no contexto do uso de drogas injetáveis.

Passa-se a denominar "uso limpo" as técnicas de cuidado na assepsia e no incentivo ao uso mais seguro de droga injetável na troca de seringas e outros equipamentos para injeção. Na experiência do PRD, a inclusão da prática de limpeza das seringas usadas com solução de hipoclorito, conforme orientação nas primeiras campanhas de prevenção à infecção pelo HIV, junto a essa população, mostrou-se ineficaz. Os relatos da dificuldade de seguir todos os passos da desinfecção das seringas usadas somam-se à necessidade de ter disponível o

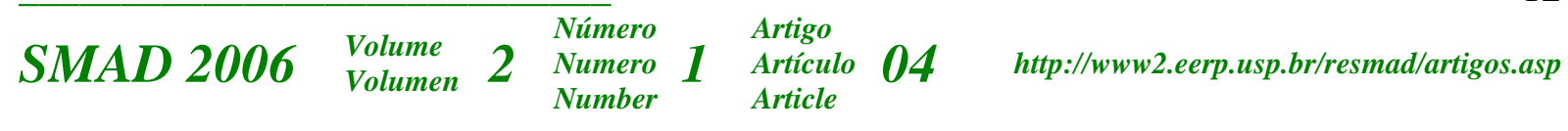


desinfetante em todos os momentos de uso, que podem ser vários em uma sessão, devido ao pouco tempo do efeito agradável da cocaína no organismo.

A prática que se mostrou mais eficiente foi a disponibilização de seringas e equipamentos estéreis, mediante a troca pelo equipamento usado. As seringas e agulhas individuais disponíveis no mercado são descartáveis. Esse fato reflete-se nos relatos de usuários de que, quando utilizam mais de uma vez a agulha, essa logo fica rombuda, sem ponta, o que faz com que "entre rasgando" (sic), machucando a pele e contribuindo para as lesões vasculares, dentre outras falhas com o equipamento. Esse cuidado já desejado pelos usuários era uma forma de atrair seu interesse pelas ações de redução de danos.

A importância de recolher os equipamentos usados está em evitar a possível reutilização por outro usuário. Estudos constataram que a sobrevivência do HIV-1, em seringas usadas por UDI, o vírus tem potencial infectante até quatro semanas em temperatura ambiente ${ }^{(28)}$. A introdução de um lugar biologicamente seguro para descarte desses equipamentos junto aos usuários não era obtida no primeiro momento. A caixa coletora, por sua cor amarela característica, acabava denunciando a condição de usuário de drogas ilícitas para alguém da vizinhança mais preconceituoso, ou a algum policial com atitude mais repressiva. Exemplo disso era o relato de que as caixas eram queimadas ou destruídas a chutes por polícias contrários ao uso de drogas. A formulação de uma carta nominal oficial do PRD que explicava os objetivos deste trabalho passou a ser um documento valioso para os usuários de drogas no momento de alguma ação repressiva da polícia.

A acomodação dos equipamentos para o "uso limpo" aos locais de uso ocorria gradualmente, juntamente com a organização das redes sociais de usuários. Com o passar do tempo a caixa coletora começa a fazer parte da mobília desses locais. Os usuários passam a adaptar esses cuidados ao seu dia-a-dia e a caixa é colocada próxima ao local de uso da droga.

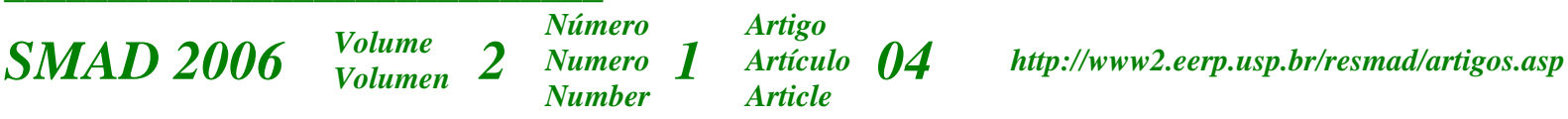


Quando o lugar de uso é a própria casa a caixa era colocada longe do alcance das crianças. Devido às precárias condições de moradia e quando estavam em situação de rua, muitos ficam impossibilitados de manter uma caixa coletora como local para desprezo das seringas. Nessas situações, a adaptação desse cuidado se faz a partir de elementos do próprio meio ambiente do usuário, como o uso de garrafas plásticas para armazenar as seringas e equipamentos usados por moradores de rua.

Os locais de punção utilizados para injetar a droga, relatados pelos UDI, são os mais diferentes. Passam pelos locais considerados seguros, como as veias dos braços, e os locais perigosos, como pescoço, até locais que podem levar a danos à saúde, como extremidades, sublingual e na genitália. Noções básicas do sistema circulatório, da diferença entre artérias (pulsantes, maior tônus e retorno de sangue forte e vermelho vivo) e veias (mais periféricas, de retorno venoso fraco e de cor mais escura), instruindo sobre a técnica correta de obter acesso venoso e os locais mais seguros são bem aceitas pelos usuários.

A mudança de injeção de cocaína para aspiração é uma forma de reduzir os danos, o que também é percebido pelos UDI. "Eu agora estou só cheirando” (sic), disse um UDI quando perguntado se ele tinha seringas para realizar trocas. Era notável a melhoria do seu estado físico.

Nas conversas sobre a epidemia de AIDS, usuários acessados refletiam sobre a possível infecção pelo HIV, tanto pelo compartilhamento como reutilização de seringas e em relações sexuais desprotegidas. Medos e dúvidas sobre sua sorologia para o HIV eram expressos. Orientava-se os serviços de referência, na medida que tomavam decisão de fazer o teste.

A melhoria da condição geral de saúde daquelas pessoas era visível. Isso se reflete na maior atenção com vestuário, higiene e saúde. Exemplo disso foi um usuário que veio mostrar

\begin{tabular}{|c|c|c|c|c|}
\hline SMAD 2006 & $\begin{array}{l}\text { Volume } \\
\text { Volumen }\end{array}$ & $\begin{array}{l}\text { Número } \\
\text { Numero } 1\end{array}$ & $\begin{array}{l}\text { Artigo } \\
\text { Artículo } 04\end{array}$ & http://www2.eerp.usp.br/resmad/artigos.asp \\
\hline
\end{tabular}


a melhora das vistosas flebites que tinha em ambos os braços, agradecendo pelo material descartável do qual era provido. Eram perceptíveis os cuidados com a aparência e em melhorar a sociabilidade. Os locais de uso também passavam a ser limpos e organizados para as visitas dos profissionais, deste estudo.

A complexidade do fenômeno do "problema das drogas", nos diferentes contextos em que se desdobra, traz limitações à avaliação quantitativa do impacto dessas ações de cuidado sobre o estado de saúde dos indivíduos nas diferentes populações usuárias de drogas. Exemplo disso, em estudo etnográfico sobre “meninos de rua” usuários de droga injetável, foi observada entre os sujeitos a valorização de lesões cutâneas e outras doenças para obter melhores resultados nas táticas de mendicância ${ }^{(29)}$.

\section{CONSIDERAÇÕES FINAIS}

Ao possibilitar cuidados profissionais de Enfermagem, com base em uma abordagem transcultural, àquelas pessoas atendidas no Programa de Redução de Danos, atuou-se sobre a lógica que produz/reproduz o problema das drogas no contexto social. A efetivação de práticas de cuidado transcultural possibilita aos usuários de drogas injetáveis uma outra forma de pensar sobre sua condição: mais que uma patologia individual, os problemas de saúde passam a ser compreendidos pela equipe e pelos usuários do programa como problemas coletivos que exigem uma posição política. Construir a identidade positiva de “cidadão usuário de drogas” a partir da (des)construção da identidade negativa de “drogado”, “viciado”, “aidético” é um processo coletivo em que cada um faz a sua parte.

As práticas de cuidados de enfermagem que primem pela busca da competência cultural acabam por banir a separação entre o campo da saúde coletiva e a clínica individual.

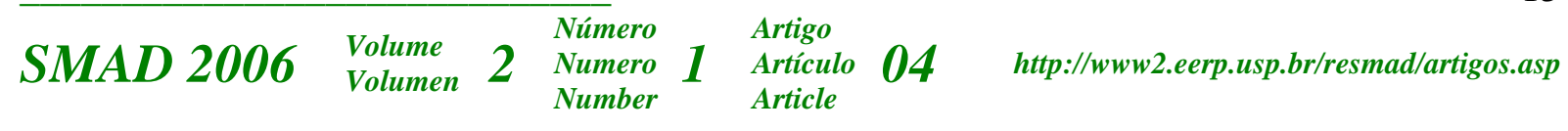


Entende-se que os princípios da redução de danos desenvolvidos nesta atuação como redutores de danos no PRD de Porto Alegre, podem ser perfeitamente replicáveis nas ações locais de equipes de saúde como aquelas do Programa de Saúde da Família. 


\section{REFERÊNCIAS BIBLIOGRÁFICAS}

1 Ministério da Saúde (BR) A Política do Ministério da Saúde para atenção integral a usuários de álcool e outras drogas. Brasília: Ministério da Saúde; 2003.

2 Baratta A. Introdução a uma sociologia da droga. In: Mesquita F, Bastos FI organizadores. Drogas e aids: estratégias de redução de danos. São Paulo: HUCITEC; 1994.

3 Zaluar A. A criminalização das drogas e o reencantamento do mal. In: Zaluar A, organizadora. Drogas e cidadania: repressão ou redução de riscos. São Paulo: Brasiliense; 1999.

4 Naciones Unidas (USA) Por qué invertir en el tratamiento del abuso de drogas: Documento de debate para la formulación de políticas. Nueva York: Naciones Unidas; 2003.

5 Poveda MAM. ¿Antropoenfermería o enfermeantropología? Cultura de los cuidados: revista de enfermaria y humanidades. Disponível em: <http://culturacuidados.ua.es/9/editorial.htm> Acesso em: 26 Ago 2003.

6 George JB. Teorias de Enfermagem. Porto Alegre: Artes Médicas; 1993.

7 Leininger MM. Care: the essence of nursing and health. Detroit: Wayne State University Press; 1988.

8 Canesqui AM.. Os estudos de antropologia da saúde/doença no Brasil na década de 1990. Ciên Saúde Colet 2003 Set; 1.8(1):109-24 [online]. Disponível em:: $<$ http://www.scielo.br/scielo. [citado 18 Setembro 2003],

9 Boehs AE. Análise dos conceitos de negociação/acomodação da teoria de M. Leininger. Rev Lat-Am Enferm 2002 Jan; 10(1)[online] Disponível em: <http://www.scielo.br> Acesso em 26 ago 2003.

10 Juntunen. A. Professional and lay in the Tanzanian village of llembula. Academic Dissertation to be presented with the assent of the Faculty of Medicine, University of Oulu, Finland, 2001.Disponível em: http://herkules.oulu.fi/isbn9514264312 Acesso em 26 de agosto de 2003.

11 Campinha-Bacote JM. Many caces: addressing diversity in health care. J. Issues Nur 2003 Jan; 8(1) [online]. Disponível em: <http://nursingworld.org/ojin/topic20/tpc20_2.htm> Acesso em: 26 Ago 2003.

12 Tripp-Reimer T. Cultural barriers to care:inverting the problem. Diabetes Pectrum, 2001; 14(1):13-22[online].Disponível

em: $<$ http://spectrum.diabetesjournals.org/cgi/content/full/14/1/13> Acesso em: 26 Agos 2003.

13 Oliveira, FA. Antropologia nos serviços de saúde: integralidade, cultura e comunicação. In: Iinterface: comunicação, saúde, educação. V. 6, n. 10, p. 63-74, 2002 . Disponível em: http://www.interface.org.br/interface\%202000/interface\%2010/artigo2.pdf Acesso em 22 de setembro de 2003.

14 Campinha-Bacote JM. Faces: addressing diversity in health care. In: Online Journal of Issues inNursing. v. 8, n. 01. Manuscript 2. 31 de janeiro de 2003. Disponível em $<$ http://nursingworld.org/ojin/topic20/tpc20 2.htm $>$ Acesso em 26 de agosto de 2003.

15 Pires D. Hegemonia médica na saúde e a Enfermagem. São Paulo: Cortez; 1989.

16 Marlatt GA. Redução de danos: estratégias para lidar com comportamentos de alto risco. Porto Alegre: Artes Médicas do Sul; 1999.

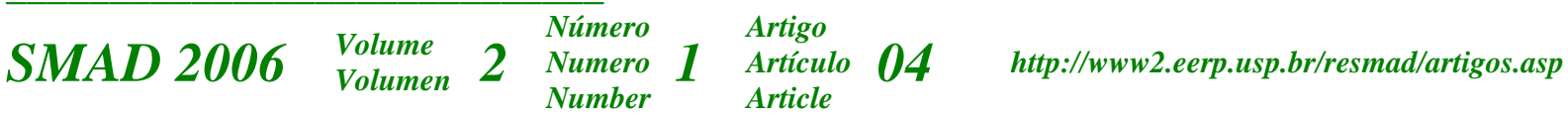


17 Bastos M, Mesquita F, Marques LF, organizadores. Troca de seringas: ciência, debate e saúde pública. Brasília: Ministério da Saúde; 1998.

18 Caiafa WT, coordenadora. Projeto Ajude-Brasil: situação de base dos usuários de drogas injetáveis dos projetos de redução de danos (PRD) (Relatório Final) Brasília: CNDST/AIDS, 1998

19 Martin D. Informação e comportamento: o exemplo da Aids. Psiquiatria na prática médica. Disponível em: < http://www.unifesp.br/dpsiq/polbr/ppm/atu5 03.htm > Acesso em: 26 Ago 2003.

20 Deslandes SF. As concepções de risco e de prevenção segundo a ótica dos usuários de drogas injetáveis. Cad Saúde Públ 2002 Jan-Fev; 18(1) [online]. Disponível em: http://www.scielo.br. Acesso em: 26 Agos 2003.

21 Heat, DB. Culture and drugs. In: OTT, PJ. Sourcebook on substance abuse: etiology, epidemiology, assessment and treatment. Boston: Allyn and Bacon,1999.

22 Velho G. A dimensão cultural e política dos mundos das drogas. In: Zaluar A, organizadora. Drogas e cidadania: repressão ou redução de riscos. São Paulo: Brasiliense, 1999.

23 Piccollo FD. "Se deixar a droga levar..." um estudo sobre as trajetórias sociais de usuários de drogas injetáveis em uma vila de Porto Alegre [dissertação]. Porto Alegre (RS): Programa de Pós-Graduação em Antropologia Social./ UFRGS; 2001.

24 Douglas M. Pureza e perigo. São Paulo: Perspectiva; 1976.

25 Spikerman IJ. Human imunodeficiency virus infection and other risk factors for skin abscesses at the side of injection and episodes of endocarditis among injection drug users. J Clin Epidem 1996 Out; (49): 49-54.

26 Duarte LFD. Indivíduo e pessoa na experiência da saúde e da doença. Ciên Saúde Col. 2003 Set; 18(1):173-83[online].Disponível em: http://www.scielo.br/scielo . Acesso em 25 Ago 2003.

27 Foucault M. O nascimento da clínica. Rio de Janeiro: Forense Universitária; 2001.

28 Abdala N. Survival of HIV-1 in syringes. J Acquire Im Def Synd Hum Retrov 1999 Jan; (20): 73-80.

29 Gregis C. Fissura da rua: corpo e ritual de uso de droga injetável entre meninos de rua [dissertação] Porto Alegre (RS):Programa de Pós-Graduação em Antropologia Social./ UFRGS; 2002. 